\title{
A GIS approach for the quantification of forest and agricultural biomass in the Basilicata region
}

\author{
D. Statuto, A. Tortora, P. Picuno \\ University of Basilicata - SAFE School of Agriculture, Forestry, Food and Environmental Sciences, \\ Potenza, Italy
}

\begin{abstract}
In this paper the attention has been focused on the energy from biomass by-product, including forest biomass and agricultural production, waste and other sources of renewable energy, available in the Basilicata Region. In order to determine the quantity of extractable biomass from the forests of the region data from plans for forest management were used. These data were imported in a Geographic Information System, in order to determine in which part of the Region there is the possibility to find greater quantity of biomass. As for the determination of the quantities of agricultural biomass, the energy crops and the agricultural waste (such as crop residues, grass cuttings, pruning, manure, waste coming from agro-food industries, etc.) were considered too. The reuse and exploitation of these wastes, while contributing to the solution of problems related to their disposal, promote their recovery as a primary source of energy. Once estimated the annual amount of biomass, the percentage of the annual energy contribution which this kind of by-product is able to ensure was determined; this renewable energy source may therefore significantly contribute to the development of the agro-forestry sector.
\end{abstract}

\section{Introduction}

Under the framework of a general analysis that has focused the attention on the energetic vocationality in the Basilicata Region (Statuto et al., 2012), in this paper the analysis especially for what concerns agricultural and forest biomass has been deepened. According with the results that were obtained so far, it was possible to notice that the energy generated

Correspondence: Dina Statuto, University of Basilicata - SAFE School of Agriculture, Forestry, Food and Environmental Sciences, Potenza, Italy

Key words: Renewable Energy, GIS, Forestry Biomass, Agricultural Biomass.

Contributions: the authors contributed equally.

Conflict of interests: the authors declare no potential conflict of interest.

CC Copyright D. Statuto et al., 2013

Licensee PAGEPress, Italy

Journal of Agricultural Engineering 2013; XLIV(s2):e125

doi:10.4081/jae.2013.s2.e125

This article is distributed under the terms of the Creative Commons Attribution Noncommercial License (by-nc 3.0) which permits any noncommercial use, distribution, and reproduction in any medium, provided the original author(s) and source are credited. from wind and solar source is able, in the regional context, to provide an extremely high potential compared with the biomass analyzed (Hoesen et al., 2010), but both these two renewable sources could not be felt as an important tool for the revitalization and the development of the agricultural and forestry sector (Statuto et al., 2012). So, while retaining as a study area the whole region, the attention was here focused on biomass only as an alternative energy source, including agricultural waste of various origin and biomass arising from the use and maintenance of forests (Yoshioka et al., 2011). This biomass, despite expressing an energy potential much lower than wind and solar power, if properly used could anyway reveal as an important energetic source being able, at the same time, to solve the environmental problems associated with their disposal.

The different biomass here considered are:

- Energy from agricultural biomass: energy derived by crops as Switchgrass pruning residues, agro-food industries residues (marc and exhausted pomace), animal manure;

- Energy from forest biomass, according with data of the forest management plans in the Basilicata Region.

\section{Material and methods}

\section{Study area}

The study area consists of the entire regional land. This area, thanks to the morphological and land cover characteristics, can be considered as a good source of renewable energy. As for the energy resulting from agricultural biomass, it was necessary to consider all areas that could potentially be used in the different energy sources. Then, for the entire region, the dat a of agricultural crops, arable crops, woody crops, breeding and industries processing agricultural products were considered. Particularly, the forest heritage of the Basilicata Region is consistent and in good vegetative conditions, its mapping is entrusted to the Regional Forest Map, while the proper management is entrusted to the forest management plans.

\section{Spatial data}

The analysis was performed on a territorial level for all the different types of renewable energy analyzed. The determination of the land suitability to cultivation of energy crops was carried out by evaluating the intrinsic characteristics of the area such as: slope, aspect, land use, in relation to physiological demanding of the considered crop. The input data originates from the Digital Terrain Model and analysis of the vegetation c over. From a territorial basis, only the agricultural areas that complying with specific characteristics (Yoshioka et al., 2011) were considered. Data on woody crops, such as grapevines, olive trees and other tree crops, from which it is possible to obtain pruning residuals, were obtained by statistic information at municipality level (ISTAT, 2011/a, ISTAT, 2011/b).

The same input map was used both for breeding and for the agrofood industries residuals. 
Table 1: Classification of diagnostic criteria for territory of Switchgrass

\begin{tabular}{|c|c|c|c|c|c|c|c|c|c|}
\hline \multicolumn{10}{|c|}{ SWITCHGRASS } \\
\hline weight & 0,15 & weight & 0,05 & weight & 0,05 & weight & 0,2 & weight & 0,4 \\
\hline & Index & & Index & & Index & & Index & & Index \\
\hline No & 0 & $\begin{array}{l}\text { Clay - sandy clay } \\
\text { - silty clay }\end{array}$ & 80 & Low & 100 & $3-4,4$ & 40 & $100-200$ & 50 \\
\hline Slow & 0 & $\begin{array}{l}\text { Clay loam } \\
\text { - silt loam }\end{array}$ & 100 & Middle & 40 & $4,5-5,5$ & 80 & $200-300$ & 70 \\
\hline Medium & 70 & Sandy loam & 100 & High & 10 & $5,6-6,5$ & 100 & $>300$ & 80 \\
\hline Balanced & 100 & $\begin{array}{l}\text { Sandy clay loam } \\
\text { - silty clay loam }\end{array}$ & 90 & Very High & 0 & $6,6-7,6$ & 80 & & \\
\hline Quick & 90 & Sand - loamy sand & 95 & & & $7,7-8,5$ & 40 & & \\
\hline Very rapid & 70 & & & & & $8,6-9,0$ & 0 & & \\
\hline
\end{tabular}

In the forest biomass context, as a territorial unit, the are covered by some previous aggregation of Municipalities - so-called, "Comunità Montane" - were assumed, since the forest management plans are still currently referred to their territories.

\section{Elaborations}

Different GIS elaborations were performed with the aim to evaluate the energy suitability in the different territorial levels about the thermal and electric potential of the different energy types, such as the agricultural biomass, resulting from energy crops, pruning residues, agro-food industries residues (marc and exhausted pomace), manures from breeding, and forest biomass, obtained from the maintenance and proper management of the woods in the Region.

\section{Energy from biomass obtained by energy crops}

In order to assess the adaptability of the area for cultivation of a plant species suitable for the production of biomass, both the characteristics of the territory and the suitable factors for the production of the species were analyzed. As the reference culture the switchgrass (Panicum virgatum L.) was taken in consideration. The Panicum virgatum is a herbaceous rhizomatous perennial plant, is drought-resistant, tolerant to salinity and acidity; it has demonstrated a good capacity to control the erosion processes too. It adapts to different types of soil, with good drainage and $\mathrm{pH}$ between 4.5 and 7.6. (Tenerelli P., 2008). Unlike most other perennial species, it's renewed by sowing. In order to evaluate the suitability of this crop to the territory of the Basilicata Region, the areas defined according with the statistical information as "non-irrigated arable land" with a slope less than $20 \%$ were considered.

Furthermore, a series of soil, climatic and environmental parameters were analyzed; their values have been standardized by attributing an index that expresses the limitation factor (from the worst $=0$ - to

Table 2: Pruning residues

\begin{tabular}{lccc} 
& & & $\begin{array}{c}\text { Total } \\
\text { residues of }\end{array}$ \\
Crop & Area (ha) & Unit residues of & $\begin{array}{c}\text { Pruning } \\
\text { [\%) }\end{array}$ \\
Grapevine & 5626 & 4,4 & 24754 \\
Olive Tree & 45744 & 3 & 137232 \\
\hline Wood Arboriculture & 2884 & 4 & 11536
\end{tabular}

the best $=100$ ). For each diagnostic feature a weight has been assigned, ranging from 0 to 1 , basing on the significance of the parameter as a limiting factor for the species. The different parameters classified according with the requirements of the species are shown in table 1.

Once the indices and weights assigned to the various diagnostic criteria, a weighted combination of the different parameters through appropriate functions of Raster Calculator was performed.

From the combination of parameters it has been possible therefore to identify the areas potentially suitable for cultivation of switchgrass; the total area in the region that was calculated amounts to about 259.000 ha. The production of switchgrass that was calculated is about 10-20 tons per hectare, while the yields of dry matter per hectare reach 11 tons per hectare.

\section{Energy from biomass obtained by pruning residues}

The crop residues have intrinsic characteristics that make them different from the main products, both for composition of the dry matter, for Lower Calorific Power (LCP) and for the water content at the time of collection. On the basis of an analysis carried out at national level, considering the whole Italian territory, it may be reasonable to consider that the effectiv e availability of fruit trees pruning destined to energy use, varies between 45 to $50 \%$ of the total amount of residues produced (ENAMA, 2011). The amount of pruning residues per hectare was therefore estimated by considering a coefficient able to quantify the unit residues per hectare of pruning (Table 2). According with the data resulting from the national context, for the determination of the amou nt of extractable biomass from residues, only $50 \%$ of the total of the pruning scraps has been considered.

The analysis was conducted on a municipal level, considering the data of land use resulting from the 5th General Census of Agriculture (ISTAT, 2010).
Table 3: estimation of scraps from olives processing

\begin{tabular}{|c|c|c|c|c|c|}
\hline $\begin{array}{l}\text { Olive } \\
\text { varieties }\end{array}$ & $\begin{array}{l}\text { Olive } \\
\text { Production } \\
\text { s (t/ha) }\end{array}$ & Area (ha) & $\begin{array}{c}\text { Olive } \\
\text { Production } \\
\text { (t) }\end{array}$ & $\begin{array}{c}\text { Virgin } \\
\text { Pomace (t) }\end{array}$ & $\begin{array}{l}\text { Exhausted } \\
\text { Pomace } \\
\text { (t) }\end{array}$ \\
\hline Vulture & 8 & 6.815 & 54.520 & 16.356 & 8.178 \\
\hline Maiatica & 10 & 38.928 & 389.280 & 116.784 & 58.392 \\
\hline
\end{tabular}


Table 4: Estimation of energetic potential for various energetic sources treated

\begin{tabular}{|c|c|c|c|c|c|}
\hline \multicolumn{6}{|c|}{ Energetic Crops: Switchgrass } \\
\hline $\begin{array}{l}\text { Total Production } \\
\text { (t/ha) }\end{array}$ & $\begin{array}{l}\text { D.M. Production } \\
\text { (t/ha) }\end{array}$ & L.C.P $(G J / t)$ & $\begin{array}{l}\text { Energetic Density } \\
\text { (MWh/ha) }\end{array}$ & $\begin{array}{l}\text { Potentially Suited } \\
\text { Territory (ha) }\end{array}$ & $\begin{array}{l}\text { Electrical Potential } \\
(\mathrm{MWh} / \mathrm{y})\end{array}$ \\
\hline 15 & 11 & 15,2 & 46,31 & 258.922 & 11.991 .917 \\
\hline \multicolumn{6}{|c|}{ Pruning residues: olive tree, grapevine, wood arboriculture } \\
\hline Crop & $\begin{array}{l}\text { Total pruning } \\
\text { residues [t/y] }\end{array}$ & $\begin{array}{l}\text { Availability residues } \\
\text { (50\% of the total }(t / y))\end{array}$ & $\begin{array}{c}\text { L.C.P } \\
(\mathrm{kWh} / \mathrm{kg})\end{array}$ & $\begin{array}{c}\text { Thermal Potential } \\
(\mathrm{MWh} / \mathrm{y})\end{array}$ & $\begin{array}{l}\text { Electrical Potential } \\
(\mathrm{MWh} / \mathrm{y})\end{array}$ \\
\hline Grapevine & 24754 & 12.377 & 4 & 49.508 & 18.318 \\
\hline Olive Tree & 137232 & 68.616 & 4 & 274.464 & 101.551 \\
\hline \multirow[t]{2}{*}{ Wood } & 11536 & 5.768 & 4 & 23.072 & 8.537 \\
\hline & & & & & 128.406 \\
\hline \multicolumn{6}{|c|}{ Residues by agro-industrial byproducts } \\
\hline Residue & Total residues [t/y] & $\begin{array}{c}\text { Usable residues }(50 \% \\
\text { of the totale }(\mathrm{t} / \mathrm{y}))\end{array}$ & $\begin{array}{c}\text { L.C.P } \\
(\mathrm{kWh} / \mathrm{kg})\end{array}$ & $\begin{array}{l}\text { Thermal Potential } \\
(\mathrm{MWh} / \mathrm{y})\end{array}$ & $\begin{array}{l}\text { Electrical Potential } \\
(\mathrm{MWh} / \mathrm{y})\end{array}$ \\
\hline Exhausted pomace & 133.140 & 66.570 & 4 & 266.280 & 98.524 \\
\hline \multirow[t]{2}{*}{ Exhausted marc } & 10.352 & 5.176 & 3,5 & 18.116 & 6.703 \\
\hline & & & & & 105.227 \\
\hline \multicolumn{6}{|c|}{ Manures } \\
\hline Breeding farms & Effluent Coeff. & Livestock Units & $\begin{array}{l}\text { Thermal Potential } \\
(\mathrm{MWh} / \mathrm{y})\end{array}$ & $\begin{array}{c}\text { Electrical Potential } \\
(\mathrm{MWh} / \mathrm{y})\end{array}$ & \\
\hline Pigs & 0.035 & 84.387 & 2.953 & 1.092 & \\
\hline \multirow[t]{2}{*}{ Oxes } & 1,441 & 90.602 & 130.557 & 48.306 & \\
\hline & & & & 49.398 & \\
\hline \multicolumn{6}{|c|}{ Forest Biomass } \\
\hline $\begin{array}{l}\text { Amount of wood } \\
\text { to taken }\left(\mathrm{m}^{3}\right)\end{array}$ & Volume $(t / m 3)$ & $\begin{array}{l}\text { Total of available } \\
\text { biomass }(t / y)\end{array}$ & $\begin{array}{c}\text { L.C.P } \\
(\mathrm{kWh} / \mathrm{kg})\end{array}$ & $\begin{array}{l}\text { Thermal Potential } \\
(\mathrm{MWh} / \mathrm{y})\end{array}$ & $\begin{array}{c}\text { Electrical Potential } \\
(\mathrm{MWh} / \mathrm{y})\end{array}$ \\
\hline 669.231 & 0,7 & 468.461 & 4,4 & 2.944 .616 & 1.089 .508 \\
\hline \multicolumn{5}{|c|}{ Total } & 13.364 .456 \\
\hline
\end{tabular}

\section{Energy from biomass obtained by agro-industrial byproducts}

Concerning the agro-food industry, it is possible to identify as significant residues for energy purposes those deriving from the olive oil industry, the exhausted pomace, and those arising by the alcoholic grapevine/wine industry, exhausted marcs.

The main by-products of the oil industry are made from pomace and vegetation water. In the absence of homogenous data about the regional production capacities of the olive oil mills and the real amount of pressed olives, an estimation of process residues was carried out in an indirect manner, starting from the production of olives for industrial use. Starting from the data concerning the average p roduction of olive oil, broken down by geographical area according with the product specification, and considering the spatial data deriving from the Agriculture Census (ISTAT, 2011), the average annual quantity of virgin pomace was calculated as about $30 \%$ of the total olive production), and then an estimation of the exhausted pomace was obtained as equal to approximately $50 \%$ of virgin pomace (Table 3 ).

Similarly, the amount of exhausted marcs usable for energy purposes was determined (ENAMA, 2011). Assuming an annual production of about 20 t/ha of grapes and calculating the part of the territory dedicated to the cultivation of vineyards, the amount of extractable exhausted marcs is equal to $4.6 \%$ of the production of wine grapes that means, for the entire regional territory, a production of about $5176 \mathrm{t} / \mathrm{y}$.

\section{Energy from biomass obtained by manures}

For the evaluation of primary energy obtainable from livestock, in this potential evaluation only the manure produced by the intensive breeding of oxes and pigs have been considered, as other types of farming all over the regional land do not use permanent shelters for the animals (Provolo G., 2005). The total amount of manure per year was so obtained by multiplying the average amount of sewage or manure produced by each animal for the total number of animals present (ISTAT, 2011/b) in the municipality of reference.

The total production of biogas, by type of dejection and animal species, can be calculated with the following formula (Provincia di Latina, 2008)

\section{$\mathrm{BP}=\mathrm{DA} \bullet \mathrm{DM} \bullet \mathrm{OM} \bullet \mathrm{BMP}$}

where:

- BP $\left[\mathrm{m}^{3} / \mathrm{y}\right]=$ Biogas Production

- DA $[\mathrm{t}]=$ Dejection amount

- DM [\%] = Dry matter

- OM [\% di DM] = Organic matter

- BMP $\left[\mathrm{m}^{3} / \mathrm{t}\right]=$ Biogas Maximum Production = Biogas Yield

The equivalent thermal energy deriving from all this scraps has been calculated without taking into account the different efficiencies of combustion, but only basing on the lower calorific power of the biogas.

\section{Energy by forest biomass}

The determination of forest biomass usable for energy purposes was estimated considering the forest management plans of the Basilicata Region with territorial reference to the "Comunità Montane", a previous form of aggregation among different Municipalities that were governing the forest utilizations with a significant environmental importance. Considering the amount of wood obtainable from forests of each "Comunità Montana" and the average 


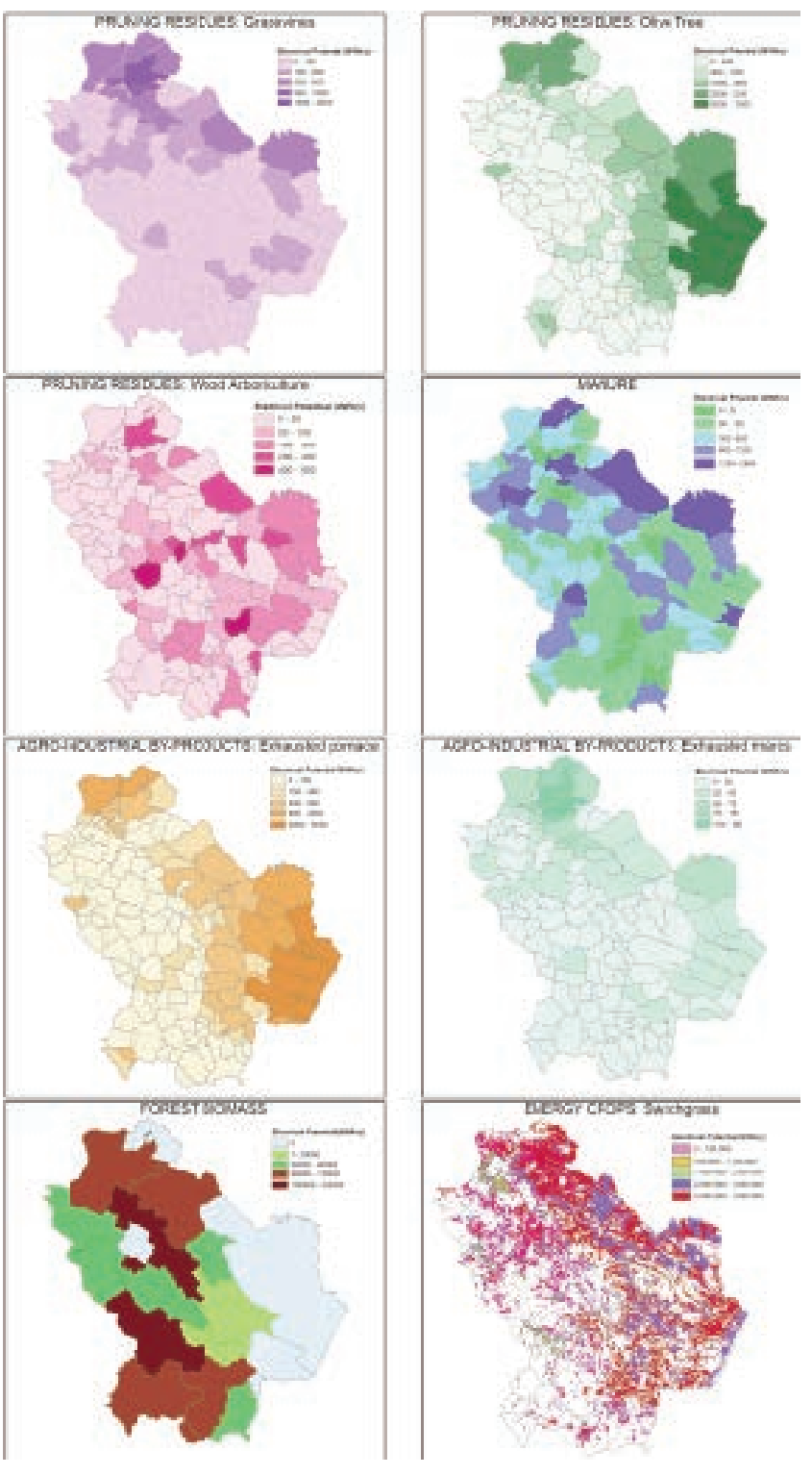

Figure 1. Estimation of Electrical Potential

volume of the different species $(0.7 \mathrm{t} / \mathrm{m} 3)$, the amount of available biomass was estimated as:

$\mathrm{TAB}=\mathrm{TW}^{*} \mathrm{~V} \quad[\mathrm{II}]$

- TAB [ton of available dry matter] = Total Available Biomass

- TW $\left[\mathrm{m}^{3}\right]=$ Total of Wood that could be obtained from the forest

$-\mathrm{V}\left[\mathrm{m}^{3} / \mathrm{t}\right]=$ Volume relating to each species and derived from tables of volume.

\section{Results}

From spatial analysis that the conducted it is clear that the regional land, thanks to its morphological characteristics and to the way of management of the agricultural and forestry activities, can ensure a considerable amount of renewable energy, that is a view to safeguard- ing the environment and the natural resources (Kinoshita et al.,2009). The estimation of the potential energy resulting from the switchgrass cultivation was determined by considering a LCP average of $15.2 \mathrm{GJ} / \mathrm{t}$ and a conversion factor of $1 \mathrm{GJ}$ equal to $0,277 \mathrm{MWh}$
DMP* LCP*0,277=ED
[III]

$\mathrm{ED} * \mathrm{PST}=\mathrm{EP}$

[IV]

where:

- DMP [t/y] = Dry Matter Production

- LCP [GJ/t] = Lower Calorific Power of Switchgrass: expressed in

- ED [MWh/y] = Energetic Density: expressed in

- PST [ha] = potentially suited Territory:

-EP $[\mathrm{MWh} / \mathrm{y}]=$ Electrical Potential

Assuming a value for the lower calorific power of biomass equal to $4 \mathrm{KWh} / \mathrm{kg}$, the thermal energy equivalent resulting from the enhancement of pruning residues for energy purposes was calculated. The estimation of the potential resulting from the enhancement, for energy purposes, of the agri-food industries scraps was made taking into account a LCP equal to $4 \mathrm{kWh} / \mathrm{kg}$ for exhauste d pomace and equal to $3,5 \mathrm{kWh} / \mathrm{kg}$ for the exhausted marcs (Provincia di Latina, 2008). In estimating the potential arising from the breeding, it has been considered an LCP of biogas equal to $5,3 \mathrm{kWh} / \mathrm{Nm}^{3}$ (Provincia di Latina, 2008), while for the forest biomass an overall average LCP equal to 4.4 $\mathrm{kWh} / \mathrm{kg}$ has been used. For the different energetic sources, the energetic electrical equivalent has been estimated considering an efficiency of electricity generation of the electrical Italian mix equal to $37 \%$ (Provincia di Latina, 2008).

The results of the estimated productivity are shown in table 4 .

\section{Discussion}

The values summarized in Table 4 show a significant imbalance between the different energy sources treated. In particular, the main significant aspect seems to be the remarkable electrical potential obtainable from energy crops, in particular the switchgrass (reference culture treated), estimated to be about $12,000 \mathrm{GWh} / \mathrm{y}$. Another important energetic source could be represented by the forest biomass obtainable according with the forest management plans, the estimated potential exceed values of $1,000 \mathrm{GWh} / \mathrm{y}$. In terms of electric potential, the enhancement, for energy pourpose, of agricultural crops, agri-food industries and farms scraps appears to be less effective. Their recovery for energy purposes, however, could be very important since it allows also to the contribution in solving the crucial environmental problem connected with their disposal. The estimated total electric potential for the entire region was therefore approximately calculated into $13,364 \mathrm{GWh} /$ year, a quantity much higher than the total regional energy needs, that was estimated by the Energy- Environmental Plan (Year 2020) into about 3,800 GWh/y.

\section{Conclusions}

The objective of this work was to estimate the potential of Basilicata region with reference to the energy capacity obtainable from the enhancement of agricultural and forest biomass (Figure 1). This theme will fit into the objectives that the European Union has set for the year 2020, in particular: a reduction of $20 \%$ in emissions of greenhouse gases, an increase up to $20 \%$ in the energy sa ving and consumption of renewable energy sources. From the performed analysis it is possible to note that the energy potential of forest biomass and that 
resulting from energy crops is well above the estimation of the expected regional energy needs for the year 2020. Furthermore, the enhancement of agro-industrial residues, although being products with a limited energy potential, will fit into the goals of the general energy efficient conservation and sustainable protection of the natural resources. Taking into account that, given the potential pollutants, these residues pose serious problems for their disposal, and are concentrated in well-defined areas (many of them dictated by the production disciplinary), it is easy to imagine that the potentially obtainable energy could give a strong impetus to the entire agro-forestry district, strongly highlighting the eco-sustainability of this sector also in the production of energy.

\section{References}

Consiglio Regionale di Basilicata, Dipartimento Attività Produttive, Politiche dell'Impresa, Innovazione Tecnologica - Ufficio Energia, (2010). PIANO DI INDIRIZZO ENERGETICO AMBIENTALE REGIONALE. [In Italian].

CRA, Consiglio per la Ricerca e la Sperimentazione in Agricoltura, (2006). Energie da biomasse agricole e forestali: miglioramento ed integrazione delle filiere dei biocarburanti e della fibra per la produzione di energia elettrica e termica - Bioenergie. [In Italian].

Disciplinary Production of "Olio extravergine di oliva "MAJATICA" a denominazione di origine protetta (DOP). [In Italian].

Disciplinary Production of OLIO EXTRAVERGINE DI OLIVA "VULTURE" A DENOMINAZIONE DI ORIGINE PROTETTA. [In Italian]

ENAMA, Ente nazionale per la Meccanizzazione Agricola (2011). Biomasse ed Energia. [In Italian].

ENEA (Italian National Agency for New Technologies, Energy and Sustainable Economic Development) Ente per le Nuove tecnologie, l'Energia e l'Ambiente, (2009). Analisi e stima quantitativa della potenzialità di produzione energetica da biomassa digeribile a livello regionale. Studio e sviluppo di un modello per unità energetiche. [In Italian].
INEA Istituto Nazionale di Economia Agraria, - Sede Regionale per la Basilicata, (2006). Carta Forestale della Basilicata. [In Italian].

ISTAT (Italian National Institute for Statistic). (2011). $6^{\circ}$ Censimento Generale dell'Agricoltura, - Utilizzazione del terreno dell'Unità Agricola - livello comunale, ISTAT, Roma, Italy [In Italian]

ISTAT (Italian National Institute for Statistic). 2011. $6^{\circ}$ Censimento Generale dell'Agricoltura, - Consistenza degli allevamenti, numero di capi - livello comunale, ISTAT, Roma, Italy [In Italian]

Kinoshita T., Inoue K., Iwao K., Kagemoto H., Yamagata Y. 2009. A spatial evaluation of forest biomas usage using GIS. Applied Energy. $86: 1-8$.

Provolo G. 2005. Manure management practices in Lombardy (Italy), Bioresource Technology. 96:145-152.

Regione Basilicata, Dipartimento Ambiente Territorio Politiche Della Sostenibilità, Ufficio Foreste e Tutela del Territorio, Piani di assestamento forestale. [In Italian].

Regione Marche, Assessorato Agricoltura 2013. Aspetti normativi ed incentivi nel settore delle agroenergie. [In Italian].

Statuto D., Tortora A., Picuno P. 2012. Classificazione di vocazionalità all'impiego di energie rinnovabili mediante grid multi-layer. Congress of AIGR (Italian Association of Agricultural Engineering). "L'Edilizia Rurale tra Sviluppo Tecnologico e Tutela del territorio", Firenze, 20 - 22 Settembre 2012 [In Italian]

Studio per la pianificazione energetico-ambientale della Provincia di Latina, (2008). Provincia di Latina, Volume 1 Tomo II Parte IV. [In Italian] http://www.provincia.latina.it/flex/cm/pages/ServeBLOB.php/L/IT/I DPagina/3094

Tenerelli P. 2008. Analisi Territoriale delle Risorse Agro-Energetiche, Tesi di Dottorato in Ingegneria del territorio e dell'ambiente agroforestale, Università degli studi di Bari. [In Italian].

Van Hoesen J., Letendre S. 2010. Evaluating potential renewable energy resources in Poultney, Vermont: A GIS-based approach to supporting rural community energy planning, Renewable Energy. 35:2114-2122.

Yoshioka T., Sakurai R., Arugac K., Sakai H., Kobayashi H., Inoue K. 2011. A GIS-based analysis on the relationship between the annual available amount and the procurement cost of forest biomass in a mountainous region in Japan, Biomass and Energy. 35:4530-4537. 